\title{
Can Biochar Couple with Algae to Deal with Desertification?
}

\author{
Xiangang Meng1,2, Wenqiao Yuan ${ }^{*}$ \\ ${ }^{1}$ School of Chemistry and Bioengineering, Lanzhou Jiaotong University, Lanzhou, China \\ ${ }^{2}$ Department of Biological and Agricultural Engineering, North Carolina State University, Raleigh, NC, USA \\ Email: ${ }^{*}$ wyuan2@ncsu.edu
}

Received 4 July 2014; revised 18 September 2014; accepted 25 September 2014

Copyright (C) 2014 by authors and Scientific Research Publishing Inc.

This work is licensed under the Creative Commons Attribution International License (CC BY). http://creativecommons.org/licenses/by/4.0/

(c) (i) Open Access

\begin{abstract}
In order to improve man-made biological soil crusts (BSCs) for desertification control and develop value-added utilization of bioenergy byproducts, preliminary experiments were carried out to understand the effect of biochar addition on algae growth in sand. Microcoleus vaginatus was chosen as the model algae and cultivated in sand with various contents of biochar $(0 \%, 2 \%, 5 \%, 8 \%$, and $10 \%$ weight of sand) that were made by rice hull gasification. Results showed that when the content of biochar in sand was $2 \%$, both algal biomass (indicated by chlorophyll-a content) and the fixed sand weight in the BSC were significantly higher than that of the control (without biochar addition) and other treatments (with $>2 \%$ biochar additions). Results from this pioneering research indicate that appropriate amount of biochar addition could increase BSC formation in sand under dry conditions and can potentially enhance sand fixation in deserts for desertification control.
\end{abstract}

\section{Keywords}

Algae, Biochar, Biological Soil Crust, Desertification, Sand Fixation

\section{Introduction}

Biological soil crusts (BSCs), or micro-biotic crusts, are formed by a consortium of microorganisms at the surface of the soil. BSCs could strengthen soil stabilization and improve the hydrological properties of crust-covered dunes [1]-[5]. The importance of BSCs for sand surface stabilization and in particular for dune stabilization in desertification control has long been acknowledged [6]-[8]. BSCs can adapt themselves to extreme environment conditions, such as high temperature, $\mathrm{pH}$ and salinity, low precipitation, strong irradiation and desiccation.

*Corresponding author. 
BSCs may be classified as cyanobacteria (algae) crusts, lichen crusts, and moss crusts [2]. Algal crusts, at the initial phase of BSC succession, provide an excellent base for the following succession stages. Algae in the crusts can secrete scytonem to against strong UV radiations, use the air dew to grow, and possess good tolerance to salt [3]-[5]. Microcoleus vaginatus is one of the main algal specie forming BSCs. Because it can bind sand grains with its super filiform texture to fix the mobile dunesurface, $M$. vaginatus has been used as a modelalgain manmade BSC studies [7] [8].

In addition to microorganisms and BSCs, another component that may play an important role in soil erosion or desertification control is biochar. Biochar has mainly been applied as a soil amendment. The focus of the past studies has mostly been limited to the agronomicstatus of the amended soils such as the cation exchange capacity, $\mathrm{pH}$, nutrient contents, vegetative growth, as well as the carbon sequestration potential of the amended soils. Positive effects of biochar on soil nutrient status and $\mathrm{C}$ sequestration, microbial community or soil biota, and greenhouse gas (GHG) mitigation have been reported [9]-[12]. However, there is little published information about effects of biochar on microorganism growth under extremely poor soil conditions, such as in deserts. If some microalgae can be successfully induced by biochar addition in deserts, it may help form BSCs as an effective way to control desertification in theory. Clearly, there is a knowledge-gap as to whether biochar can improve physiochemical properties of soils and enhance BSC formation in deserts or desert-like environments. Thus, the objective of this study was to explore the effect of biochar addition to sand on algae growth and sand fixation in the form of BSC.

\section{Materials and Methods}

\subsection{Algae Seed Culture}

M. vaginatus (UTEX B2220) was obtained from the University of Texas at Austin Culture Collection of Algae (Austin, TX). It was cultured in BG-11 medium according to the medium recipe of the University of Texas at Austin Culture Collection of Algae. The culture was performed in an air-conditioned room $\left(25^{\circ} \mathrm{C} \pm 2{ }^{\circ} \mathrm{C}\right)$ under $40 \mu \mathrm{mol}$ photons $\mathrm{m}^{-2} \cdot \mathrm{s}^{-1}$ light intensity and 16:8 h light/dark photoperiod in a 2-L airlift photo-bioreactor for 14 days. Then the algae were harvested by filtration followed by drying in an oven at $30^{\circ} \mathrm{C}$ for $48 \mathrm{~h}$. Then, the dried $M$. vaginatus biomass were manually ground with a mortar and pestle and stored under $4^{\circ} \mathrm{C}$ in a refrigerator until experiments.

\subsection{Biochar Preparation and Algae Culture in Sand}

The biochar was made from rice hulls by top-lit updraft gasification. The biochar was then ground with a mortar and pestle, sieved by a 1-mm screen and autoclaved. The sands were obtained from a local store and also sieved by the 1-mm screen and autoclaved. Five blends of biochar and sand were made with biochar contents ranging from $0 \%$ (the control) to $2 \%, 5 \%, 8 \%$ and $10 \%$ weight of the sand.

Ten grams of the sand-biochar mixture was then placed into a glass petri dish with three replications. Driedalgae powder of $0.1 \mathrm{~g}$ was dissolved into 30-ml deionized water as the inoculant. Every petri dish was then incubated with 2-ml algaeinoculant by uniformly spraying the algal solution onto the surface of the sand. All dishes wereopen cultured under $40 \mu \mathrm{mol}$ photons $\mathrm{m}^{-2} \cdot \mathrm{s}^{-1}$ light intensity and 16:8 h light/dark photoperiod in a reactor $\left(30^{\circ} \mathrm{C} \pm 1^{\circ} \mathrm{C}\right)$ for 28 days. In the first 5 days, 2-ml water was sprayed into each dish to support microalgae growth. After 5 days, no more water was provided while the reactor was heated and air-circulated to achieve hot and dry conditions.

\subsection{Sand Fixation Measurement}

In order to evaluate the capacity of sand fixation of the BSC, the weight of fixed sands was measured at the end of the 28-day culture period according to the following procedures. First, the petri dish was held upright so unfixed sands dropped from the petri dish. Then, the petri dish was gently rotated for $360^{\circ}$ in the upright position to make sure that all unfixed sands were detached from the petri dish. The unfixed sands were collected and weighed to calculate the weight of fixed sands.

\subsection{Biomass Analysis of BSCs}

Samples (along with fixed sand and biochar) were collected for the measurements of chlorophyll-a. Because it is 
difficult to separate sand and biochar from algae, chlorophyll-acontent was used as the index of algal biomass accumulation in the BSC following the method of Chen [13]. Briefly, the entire sample in the petri dish ( 10 g) was extracted bya mixture of $90 \%$ acetone $(20 \mathrm{ml})$ and dimethyl sulfoxide $(2.5 \mathrm{ml})$ at $20^{\circ} \mathrm{C}$ for $36 \mathrm{~h}$ in the dark. The supernatant was then measured for fluorescence density $\left(\mathrm{Y}_{1}\right)$ at $430 \mathrm{~nm}$ excitation wavelength and $670 \mathrm{~nm}$ emission wavelength using a micro-plate reader (Synergy Mx, Winooski, Vermont). Then, the extraction was added with $0.5-\mathrm{ml} 1 \mathrm{M}$ HCland measured for fluorescence density $\left(\mathrm{Y}_{2}\right)$ at 430-nm excitation wavelength and 670-nm emission wavelength again. Chlorophyll-a concentration $\left(D_{\text {chla }}, \mathrm{mg} / \mathrm{g}\right)$ was obtained from the fowling equation [13]:

$$
D_{\text {chla }}=22.5 \times 10^{-3} \times \frac{Y_{1}-Y_{2}-0.281}{1795.5}
$$

\subsection{Statistical Analysis}

Statistical analysis was carried out using the statistical software SPSS.20. Treatment effects were analyzed by one-way analysis of variance. Correlations were analyzed by Pearson's Model.

\section{Results and Discussion}

Chlorophyll-a contents and fixed sand weights are shown in Table 1. Data are expressed as mean \pm standard deviation, and the letter in the bracket following the data represents statistical significance (different letters mean the treatments are significantly different at $95 \%$ confidence level). It is apparent that $2 \%$ biochar addition had significantly higher chlorophyll-a content and more fixed sands than the control, while the other treatments were not significantly different from the control or each other.

The correlation between chlorophyll-a content and fixed sand weight can be seen from Figure 1. The $\mathrm{R}^{2}$ of 0.80 suggests that fixed sand weight was strongly related to algal biomass represented by chlorophyll-a content. In other words, it can be concluded that sand fixation was attributed to algae growth in the biological crust.

Why canbiochar improve $M$. vaginatus growth on sands under dry conditions? First, contrasting to sands, rice hull biochar could provide some nutrients to the algae. Karmakar et al. [14] studied the effect of rice hullbiocharon the growth and yield of rice in the acid lateritic soil of India. They showed that the application of the biochar improved soil properties by increasing soil $\mathrm{pH}$, organic carbon, and available nutrients. Rice hullbiochar has also been shown to contain $\mathrm{Ca}, \mathrm{Mg}$, and $\mathrm{Na}$, a fraction of which may be readily leached and therefore mineralized and in some cases could stimulate microbial activity [15] [16]. Secondly, some physical properties of bi-

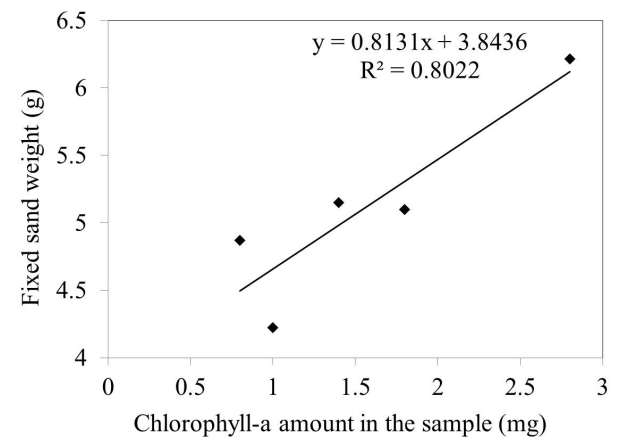

Figure 1. The correlation between chlorophyll-a amount and fixed sand weight.

Table 1. Chlorophyll-a content and fixed sand weight of the treatments.

\begin{tabular}{cccccc}
\hline \multicolumn{5}{c}{ Different content of biochar in sand (w/w) } \\
\hline & $0 \%$ & $2 \%$ & $5 \%$ & $8 \%$ & $10 \%$ \\
\hline$D_{\text {chla }}(\mathrm{mg})$ & $1.8 \pm 0.15$ (a) & $2.8 \pm 0.35$ (b) & $1.0 \pm 0.40$ (a) & $0.8 \pm 0.37$ (a) & $1.4 \pm 0.32$ (a) \\
Fixed sands (g) & $5.1 \pm 0.65$ (a) & $6.2 \pm 1.44$ (b) & $4.2 \pm 0.89$ (a) & $4.9 \pm 0.51$ (a) & $5.2 \pm 0.82$ (a) \\
\hline
\end{tabular}


ochar, such as high surface area and porosity and high water holding capacities are also likely to improve the ability of the soil to absorb, and possibly slowly release water and organic mattersor nutrients [17]. Abundant BSCs were found on the desert sand surfaces, growing especially in cool periods (fall and early spring) with limited moisture, such as with air dew, fog, or temporary rainfall [18]. M. vaginatus as a major species of desert algae has super ability of drought tolerance; however, it still needs some water to grow. Biochar, which can capture and hold water and slowly release it, has probably helped algae growth. Thirdly, because of the numerous macro- and micro-pores of biochar, they can change the bulk density of poor soil and improve its ventilation conditions [19]. Such conditions are helpful to desert algae's spore germination and development, as well as reproductivity of filaments.

\section{Conclusion}

This is a pioneering study in using biochar to improve biological soil crust formation on sand under dry conditions. It was found that the content of biochar in sand had significant effects on algae growth and sand fixation. Based on preliminary results, $2 \%$ biochar (from rice hull gasification) in sand significantly increased the formation of biological crust. This research concludes that biochar and algae may be coupled to deal with desertification, but further investigations are needed to understand the effect of biochar properties and various species of algae or other microorganisms on BSC formation in real desert environments.

\section{Acknowledgements}

The authors gratefully appreciate Mr. Arthur James and Dr. Mike Boyette at North Carolina State University for their assistance in making biochar. This work was financially supported by the US National Science Foundation (Award \# CMMI-1239078), the startup fund of North Carolina State Universityand China Scholarship Council (CSC20125030).

\section{References}

[1] Mazor, G., Kidron, G.J., Vonshak, A. and Abeliovich, A. (1996) The Role of Cyano-Bacterial Exopolysaccharides in Structuring Desert Microbial Crusts. FEMS Microbiology Ecology, 21, 121-130.

[2] Belnap, J., Rosentreter, R., Leonard, S., Kaltenecker, J.H., Williams, J. and Eldridge, D. (2001) Biological Soil Crusts: Ecology and Management. Technical Reference 1730-2, US Department of the Interior Bureau of Land Management Printed Materials Distribution Center BC-650-B.

[3] Rao, B.Q., Wu, P.P., Dauta, A., Li, D.H. and Liu, Y.D. (2011) Effects of UV-B Radiation on Growth and Ultrastructures of Cyano-Bacterial Crusts under Greenhouse Conditions. Acta Sci Circumstaniae, 3, 649-657.

[4] Rao, B.Q., Liu, Y.D., Wang, W.B., Hu, C.X., Li, D.H. and Lan, S.B. (2009) Influence of Dew on Biomass and Photosystem II Activity of Cyanobacterial Crusts in the Hopqi Desert, Northwest China. Soil Biology Biochemistry, 41, 2387-2393. http://dx.doi.org/10.1016/j.soilbio.2009.06.005

[5] Lan, S.B., Wu, L., Zhang, D.L., Hu, C.X. and Liu, Y.D. (2010) Effects of Drought and Salt Stresses on Man-Made Cyanobacterial Crusts. European Journal of Soil Biology, 6, 381-386. http://dx.doi.org/10.1016/j.ejsobi.2010.08.002

[6] Bowker, M.A., Reed, S.C., Belnap, J. and Philips, S.L. (2002) Temporal Variation in Community Composition, Pigmentation and Fv/Fm of Desert Cyanobacterial Soil Crusts. Microbial Ecology, 43, 13-25. http://dx.doi.org/10.1007/s00248-001-1013-9

[7] Hu, C.X., Liu, Y.D. and Zhang, D.L. (2002) Cementing Mechanism of Algal Crusts from Desert Area. Chinese Science Bulletin, 16, 1361-1368. http://dx.doi.org/10.1360/02tb9301

[8] Hu, C.X. and Liu, Y.D. (2003) Primary Succession on Algal Community Structure in Desert Soil. Acta Botanica Sinica, 8, 917-924.

[9] van Straalen, N.M. (1998) Evaluation of Bio-Indicator Systems Derived from Soil Arthropod Communities. Applied Soil Ecology, 9, 429-437. http://dx.doi.org/10.1016/S0929-1393(98)00101-2

[10] Gundale, M.J. and DeLuca, T.H. (2006) Temperature and Substrate Influence the Chemical Properties of Charcoal in the Ponderosa Pine/Douglas-Firecosystem. Forest Eco and Management, 231, 86-93. http://dx.doi.org/10.1016/j.foreco.2006.05.004

[11] Sharkawi, H., Yamamoto, S. and Honna, T. (2006) Rice Yield and Nutrient Uptake as Affected by Cyano-Bacteria and Soil Amendments-A Pot Experiment. Journal of Plant Nutrition and Soil Science, 169, 809-815. http://dx.doi.org/10.1002/jpln.200522013 
[12] Asai, H., Samson, B.K., Stephan, H.M., Songyikhangsuthor, K., Homma, K., Kiyono, Y., Inoue, Y., Shiraiwa, T. and Horie, T. (2009) Biochar Amendment Techniques for Upland Rice Production in Northern Laos 1. Soil Physical Properties, Leaf SPAD and Grain Yield. Field Crops Research, 111, 81-84. http://dx.doi.org/10.1016/j.fcr.2008.10.008

[13] Chen, L., Liu, Y. and Song, L. (2002) The Function of Exopolysaccharides of Microcoleus vaginatus in the Formation of Desert Soil. Acta Hydrobiologica Sinica, 26, 155-159.

[14] Masulili, A., Utomo, W.H. and Syechfani, M.S. (2010) Rice Husk Biochar for Rice Based Cropping System in Acid Soil 1. The Characteristics of Rice Husk Biochar and Its Influence on the Properties of Acid Sulfate Soils and Rice Growth in West Kalimantan, Indonesia. Journal of Agricultural Science, 2, 39-42.

[15] Lehmann, J. and Joseph, S. (2009) Biochar for Environmental Management: Science and Technology. Earthscan, London.

[16] Steiner, C., Das, K.C., Garcia, M., Förster, B. and Zech, W. (2008) Charcoal and Smoke Extract Stimulate the Soil Microbial Community in a Highly Weathered Xanthic Ferralsol. Pedobiologia, 51, 359-366. http://dx.doi.org/10.1016/j.pedobi.2007.08.002

[17] Liang, B., Lehmann, J., Solomon, D., Kinyangi, J., Grossman, J., O’Neill, B., Skjemstad, J.O., Thies, J., Luizão, F.J., Petersen, J. and Neves, E.G. (2006) Black Carbon Increases Cation Exchange Capacity in Soils. Soil Science Society of America Journal, 70, 1719-1730. http://dx.doi.org/10.2136/sssaj2005.0383

[18] Zhang, B., Zhang, Y., Zhao, J., Wu, N., Chen, R. and Zhang, J. (2009) Microalgal Species Variation at Different Successional Stages in Biological Soil Crusts of the Gurbantunggut Desert, Northwestern China. Biology and Fertility of Soils, 45, 539-547. http://dx.doi.org/10.1007/s00374-009-0364-0

[19] Major, J., Lehmann, J., Rondon, M. and Goodale, C. (2010) Fate of Soil-Applied Black Carbon: Downward Migration, Leaching and Soil Respiration. Global Change Biology, 16, 1366-1379. http://dx.doi.org/10.1111/j.1365-2486.2009.02044.x 
Scientific Research Publishing (SCIRP) is one of the largest Open Access journal publishers. It is currently publishing more than 200 open access, online, peer-reviewed journals covering a wide range of academic disciplines. SCIRP serves the worldwide academic communities and contributes to the progress and application of science with its publication.

Other selected journals from SCIRP are listed as below. Submit your manuscript to us via either submit@scirp.org or Online Submission Portal.
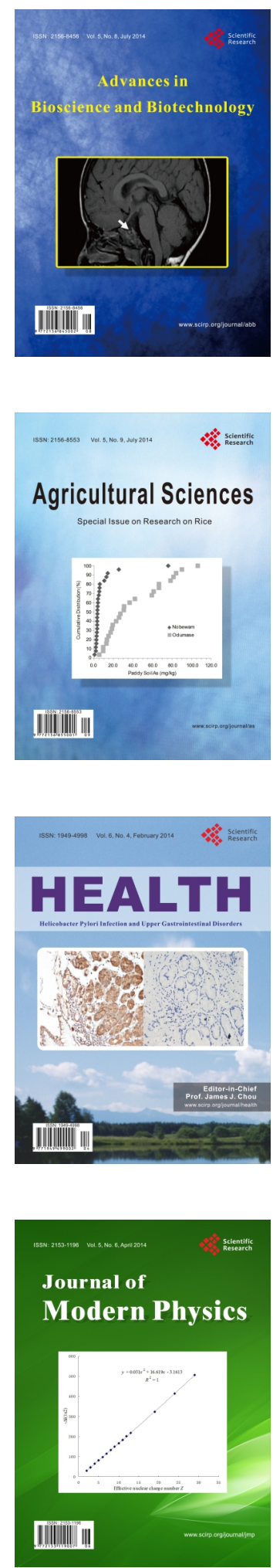
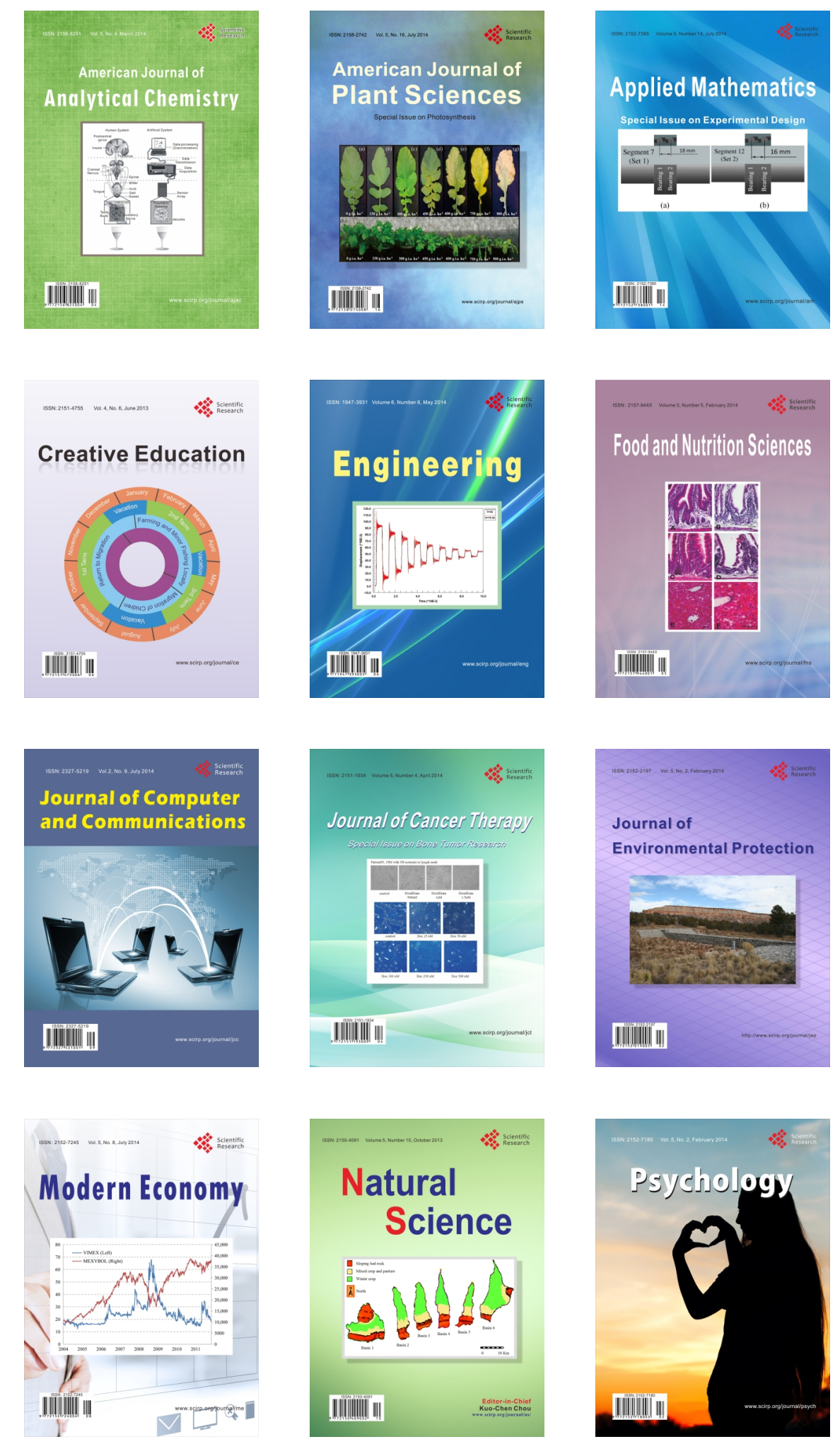